\title{
A genomic approach to understand interactions between Streptococcus pneumoniae and its bacteriophages
}

\author{
Philippe Leprohon ${ }^{1,2}$, Hélène Gingras ${ }^{1,2}$, Siham Ouennane ${ }^{3,4}$, Sylvain Moineau $u^{3,4}$ and Marc Ouellette ${ }^{1,2^{*}}$
}

\begin{abstract}
Background: Bacteriophage replication depends on bacterial proteins and inactivation of genes coding for such host factors should interfere with phage infection. To gain further insights into the interactions between S. pneumoniae and its pneumophages, we characterized S. pneumoniae mutants selected for resistance to the virulent phages SOCP or Dp-1.

Results: S. pneumoniae R6-SOCPR and R6-DP1 ${ }^{R}$ were highly resistant to the phage used for their selection and no cross-resistance between the two phages was detected. Adsorption of SOCP to R6-SOCPR was partly reduced whereas no difference in Dp-1 adsorption was noted on R6-DP1 ${ }^{R}$. The replication of SOCP was completely inhibited in R6-SOCPR while Dp-1 was severely impaired in R6-DP1 ${ }^{R}$. Genome sequencing identified 8 and 2 genes mutated in $R 6-S O C P^{R}$ and $R 6-D P 1^{R}$, respectively. Resistance reconstruction in phage-sensitive S. pneumoniae confirmed that mutations in a GntR-type regulator, in a glycerophosphoryl phosphodiesterase and in a Mur ligase were responsible for resistance to SOCP. The three mutations were additive to increase resistance to SOCP. In contrast, resistance to Dp-1 in R6-DP1 ${ }^{\mathrm{R}}$ resulted from mutations in a unique gene coding for a type IV restriction endonuclease.
\end{abstract}

Conclusion: The characterization of mutations conferring resistance to pneumophages highlighted that diverse host genes are involved in the replication of phages from different families.

Keywords: Streptococcus pneumoniae, Bacteriophage, Resistance, Whole genome sequencing, GntR regulator

\section{Background}

Streptococcus pneumoniae is an opportunistic colonizer of the nasopharynx and the causative agent of many serious diseases such as pneumonia, sepsis, meningitis and otitis media. Initially, strains of $S$. pneumoniae were exquisitely susceptible to penicillin, and $\beta$-lactam antibiotics were the recommended empirical treatment against pneumococcal diseases. However, pneumococci resistant to $\beta$-lactams and other classes of antibiotics now represent a major burden due to the spread of multidrug resistant clones [1-3] and penicillin-resistant pneumococci are listed among the most

\footnotetext{
* Correspondence: Marc.Ouellette@crchul.ulaval.ca

${ }^{1}$ Centre de recherche en Infectiologie du Centre de Recherche du CHU de Québec, Université Laval, 2705 Boul. Laurier, Québec, QC, Canada, G1V 4G2

${ }^{2}$ Département de Microbiologie, Infectiologie et Immunologie, Faculté de Médecine, Université Laval, 1050, avenue de la Médecine, Québec, QC, Canada, GIV OA6

Full list of author information is available at the end of the article
}

serious antibiotic resistance threats [4]. Antimicrobial resistance will require innovation not only in the development of new antibiotics but also in alternative treatment strategies and, in this context, biological therapeutics were included among the seven key areas of antimicrobial resistance for which research is urgently needed [5].

Bacteriophage (phage) therapy represents one of the promising alternatives against multidrug resistant pathogens. Strategies include the use of isolated virions but also some of their products like endolysins, a family of peptidoglycan hydrolases released at the terminal stage of phages replication cycle for the lysis of infected cells and phage progeny release. In the case of S. pneumoniae, a number of studies have demonstrated the potential of phage-produced endolysins against otitis media [6], bacteremia [7] and pneumonia $[8,9]$. In contrast, while pneumophages have been repeatedly described in the literature [10-18], studies evaluating the use of whole 
virions have lagged behind. A high proportion of $S$. pneumoniae clinical isolates are lysogens [19-21] and the vast majority of pneumophages currently identified are temperate phages. However, because temperate phages have the ability to transfer host DNA and/or increase virulence [22], virulent phages are thought to be better suited for biocontrol purposes.

Very few virulent bacteriophages infecting S. pneumoniae have been isolated. Despite the isolation of Omega phages several decades ago [18], the pneumophages Dp-1 and $\mathrm{Cp}-1$ are the only lytic phages that remain available in curated bacteriophage collections. Phage Dp-1 was the first virulent pneumophage to be isolated [12]. It belongs to the Siphoviridae family and has a DNA genome of $56,506 \mathrm{bp}$ coding for 72 putative proteins, 39 of which could be annotated based on sequence homology [23]. Phage Cp-1 was isolated in 1981 [16] and is a member of the Podoviridae family. Its DNA genome of 19,345 bp contains 25 open reading frames $>50$ nucleotides of which a third could be assigned a function based on sequence homology at the protein level with gene products from bacteriophage phi29 infecting Bacillus subtilis [24]. The infectivity of Dp-1 and Cp-1 was shown to require choline in the pneumococcus cell wall [12]. More recently, a natural variant of Cp-1 called SOCP with a genome of 19,347 bp and 31 single nucleotide variations has been described [25]. The annotation of the genome of SOCP revealed 27 open reading frames, each preceded by a putative ribosome-binding site, and a putative function could be assigned to 12 proteins [25].

One of the perceived drawbacks of phage therapy is the likely emergence of phage-resistant derivatives or clones [26]. Such phage resistance phenotype may be due to dedicated defense mechanisms harboured by some strains, including restriction-modification systems and CRISPR-Cas systems or may be due to the absence of specific host factors such as phage receptors or to the presence of interfering capsular polysaccharides [27]. In addition to phage adsorption at the cell surface, many other steps of the phages lytic cycle such as replication, transcription and translation also likely depend on bacterial cytoplasmic gene products. The absence or inactivation of some of these genes could prevent the lysis of phageinfected cells. Therefore, an in-depth understanding of the bacterial factors involved in phage-host interactions is needed to optimize the selection of appropriate therapeutic phage.

Here, we identified host factors involved in the pneumophage infection process. We first confirmed, using molecular tools, the role of the capsule in protecting pneumophage infection. We also infected the unencapsulated S. pneumoniae R6 with virulent phage $\mathrm{Dp}-1$ and SOCP and selected spontaneous bacteriophage-insensitive mutants. Genome sequencing of the mutants and functional analysis revealed diverse mutations implicated in resistance to pneumophages.

\section{Results}

Interaction of bacteriophages SOCP and DP-1 with S. pneumoniae

The unencapsulated strain S. pneumoniae R6 is highly sensitive to pneumophages SOCP and Dp-1 (Table 1). This is in sharp contrast to its encapsulated S. pneumoniae D39 ancestor which demonstrates complete resistance (Table 1). The pneumococcal capsule had previously been shown to inhibit infection by omega pneumophages [27] and it is possible that a similar protective role also occur against bacteriophages SOCP and Dp-1. The role of the pneumococcal capsule in the resistance to phages SOCP and Dp-1 was assessed by generating a S. pneumoniae D39 derivative inactivated for the gene cps2C (SPD_0317). The inactivation of cps2C was previously shown to result in a severe reduction in capsule size [28]. Capsular serotyping with an antisera directed against type 2 pneumococcal capsular polysaccharides confirmed the

Table 1 Sensitivity of S. pneumoniae strains to bacteriophages SOCP and Dp-1

\begin{tabular}{|c|c|c|c|c|c|c|}
\hline \multirow[t]{3}{*}{ S. pneumoniae strains } & \multirow[t]{3}{*}{$\operatorname{cps} 2 C$ status $^{a}$} & \multirow[t]{3}{*}{ Capsule $^{b}$} & \multicolumn{4}{|l|}{ Phages } \\
\hline & & & \multicolumn{2}{|l|}{ SOCP } & \multicolumn{2}{|l|}{ Dp-1 } \\
\hline & & & Phage titer (PFU/mL) & $\mathrm{EOP}^{\mathrm{C}}$ & Phage titer (PFU/mL) & $\mathrm{EOP}^{\mathrm{C}}$ \\
\hline R6 & NA & - & $10^{9}$ & 1 & $10^{10}$ & 1 \\
\hline D39 & WT & + & 0 & $N A$ & 0 & $N A$ \\
\hline $\mathrm{D} 39^{\Delta \operatorname{cps} 2 C}$ & $\mathrm{KO}$ & - & $10^{9}$ & 1 & $10^{10}$ & 1 \\
\hline D39 $9^{\text {cps2C-rspl }}$ & WT & + & 0 & $N A$ & 0 & NA \\
\hline R6-SOCPR & NA & - & 1 & $10^{-9}$ & $10^{10}$ & 1 \\
\hline $\mathrm{R} 6-\mathrm{DP} 1^{\mathrm{R}}$ & $N A$ & - & $10^{9}$ & 1 & $10^{2}$ & $10^{-8}$ \\
\hline
\end{tabular}

${ }^{a}$ WT, S. pneumoniae D39 wild type allele; KO, S. pneumoniae D39 allele inactivated by insertion-duplication mutagenesis; NA, Not applicable since the gene is absent in S. pneumoniae R6 due to the deletion of the capsule locus [77, 78]

$\mathrm{b}+{ }^{\prime}$ and ' - ' respectively indicate the presence and absence of the pneumococcal capsule as determined by the Quellung reaction (see Fig. 1) ${ }^{C} E O P$, efficiency of plaquing. Represents the ratio of phage titers from the test strain to the indicator strain S. pneumoniae R6 WT. Measured from three independent triplicates. $N A$, not applicable because of absolute bacteriophage resistance 
absence of detectable capsule in S. pneumoniae D39 ${ }^{\Delta \text { cps2C }}$ (Fig. 1). S. pneumoniae D39 $9^{\Delta \mathrm{cps} 2 \mathrm{C}}$ also had the same level of sensitivity to SOCP and Dp-1 as S. pneumoniae R6 (Table 1 ). Reverting $\operatorname{cps} 2 C$ to a WT version in $\mathrm{D} 39^{\Delta \operatorname{cps} 2 C}$ restored the capsule and abrogated phage sensitivity in the resulting S. pneumoniae D39 ${ }^{\text {cps2C-rpsL }}$ transformant (Fig. 1 and Table 1). The pneumococcal serotype 2 capsule is thus a major determinant of resistance against virulent pneumophages.

To further our understanding of interactions between pneumophages and S. pneumoniae R6, we selected bacteriophage-insensitive mutants (see Methods). One mutant resistant to phage SOCP and another resistant to phage Dp-1 were chosen for further characterization and these were named $S$. pneumoniae $\mathrm{R} 6-\mathrm{SOCP}^{\mathrm{R}}$ and $\mathrm{R} 6$ $\mathrm{DP} 1^{\mathrm{R}}$, respectively (Table 1 ). The bacteriophageinsensitive mutants R6-SOCP ${ }^{\mathrm{R}}$ and R6-DP1 ${ }^{\mathrm{R}}$ mutants had unaltered growth kinetics compared to S. pneumoniae R6 wild-type (WT) (Additional file 1). Both mutants also displayed a normal morphology under electronic microscopy and had unaltered cell wall thickness compared to their S. pneumoniae R6 parent (Additional file 2). The

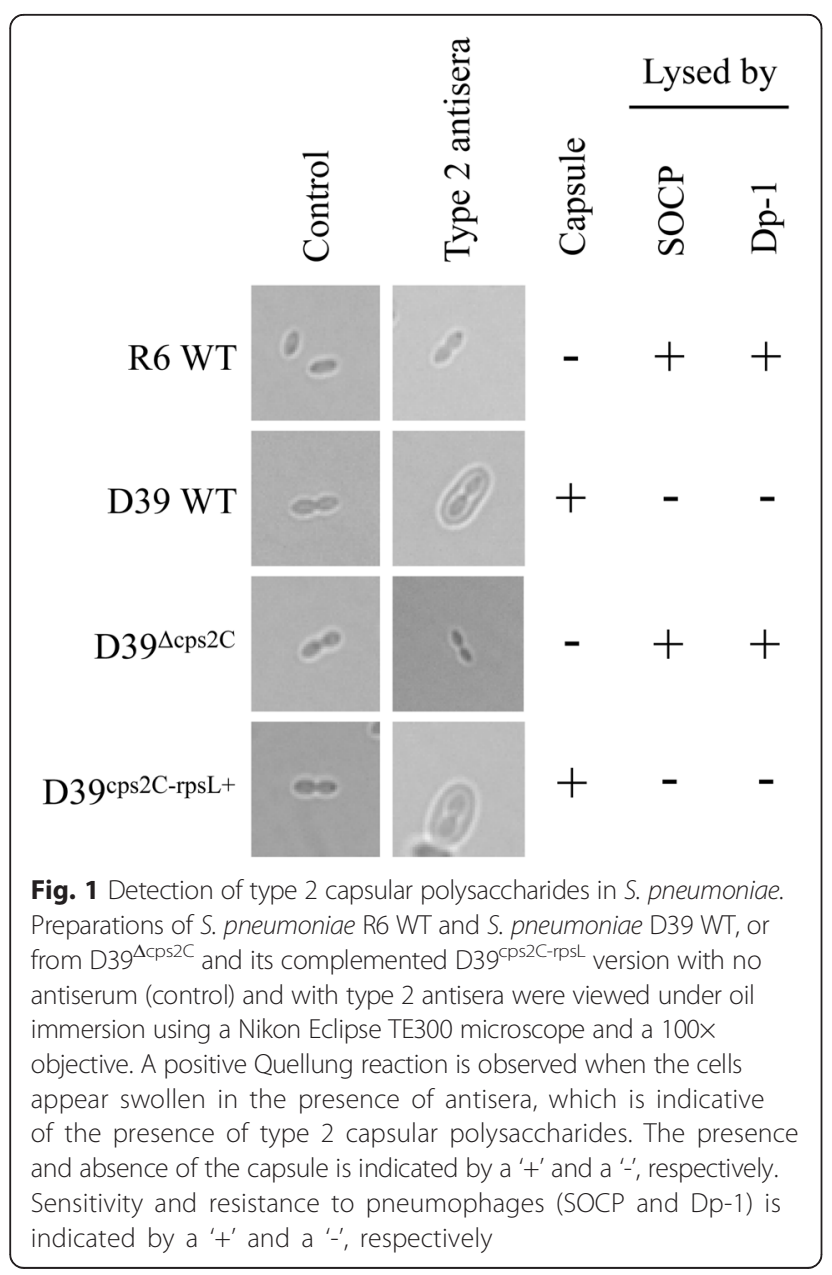

R6-SOCP ${ }^{\mathrm{R}}$ and $\mathrm{R} 6-\mathrm{DP} 1^{\mathrm{R}}$ mutants were highly resistant to the phage used for their selection. There were no detectable plaques when a SOCP bacteriophage suspension $\left(10^{9} \mathrm{PFU} / \mathrm{mL}\right)$ was spotted onto a lawn of R6-SOCP ${ }^{\mathrm{R}}$ (Table 1). In contrast, spotted SOCP bacteriophages onto a lawn of $S$. pneumoniae R6 WT resulted in a confluent zone of clearing (Table 1). Similarly, the efficiency of plaquing (EOP) of $\mathrm{Dp}-1$ on $\mathrm{R} 6-\mathrm{DP} 1^{\mathrm{R}}$ was determined to $10^{-8}$ when compared to the indicator strain S. pneumoniae R6 (Table 1). The mutants $\mathrm{R} 6-\mathrm{SOCP} \mathrm{R}^{\mathrm{R}}$ and $\mathrm{R} 6-\mathrm{DP} 1^{\mathrm{R}}$ remained sensitive to $\mathrm{Dp}-1$ and SOCP, respectively (Table 1 ).

\section{Adsorption and replication of pneumophages SOCP and Dp-1}

To gain further insights into the step of the infective cycle that is blocked in the resistant mutants, we first tested whether bacteriophage adsorption was prevented in $\mathrm{R} 6-\mathrm{SOCP} \mathrm{R}^{\mathrm{R}}$ and R6-DP1 $1^{\mathrm{R}}$. Adsorption assays showed that pneumophages SOCP and Dp-1 efficiently adsorbed to S. pneumoniae R6 but that adsorption of SOCP was reduced on mutant R6-SOCP ${ }^{\mathrm{R}}$ (Fig. 2). SOCP adsorption levels on $\mathrm{R} 6-\mathrm{SOCP}^{\mathrm{R}}$ still remain substantially high however (Fig. 2), suggesting additional mechanisms for resistance (Table 1 ). In contrast, the S. pneumoniae R6$\mathrm{DP} 1^{\mathrm{R}}$ mutant adsorbed DP-1 bacteriophages as efficiently as S. pneumoniae R6 (Fig. 2). The resistance of both mutants thus likely affect a step of the lytic cycle beyond the phage adsorption process.

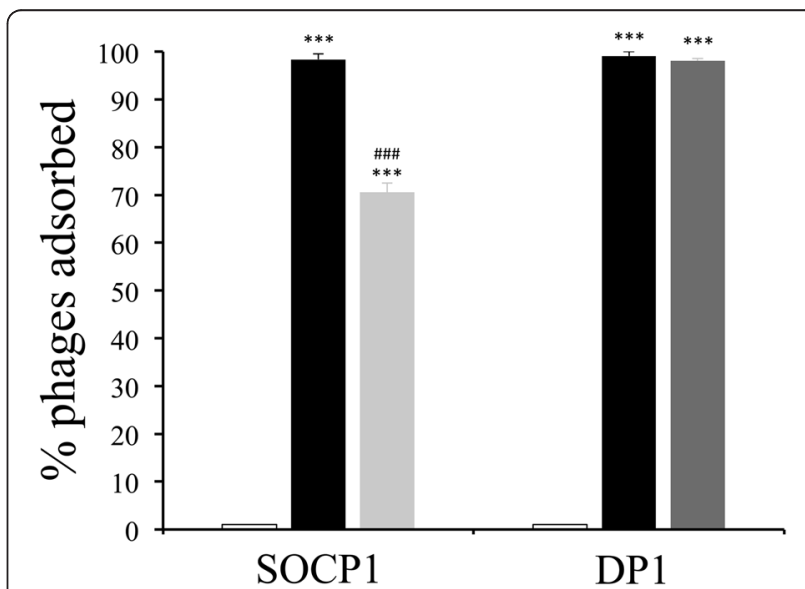

Fig. 2 Adsorption of phages SOCP and Dp-1 on S. pneumoniae strains. Rates of adsorption of SOCP and Dp-1 on S. pneumoniae R6 WT (black), R6-SOCPR (light grey) or R6-DP1 ${ }^{R}$ (dark grey). No adsorption occurred in the absence of bacteria (empty bar). Adsorption of SOCP on R6-DP $1^{R}$ and adsorption of Dp-1 on R6-SOCP ${ }^{R}$ was not measured since no bacteriophage cross-resistance occurred in the mutants (see Table 1). ${ }^{* * * *}$ denotes significant differences in adsorption compared to the mock control ( $p<0.0001$; one-way non-parametric ANOVA). \#\#\#denotes significant differences in adsorption compared to R6 WT ( $p<0.0001$; one-way non-parametric ANOVA) 
We next assayed whether the intracellular replication of pneumophages is impaired in S. pneumoniae R6-SOCP ${ }^{\mathrm{R}}$ and R6-DP1 ${ }^{\mathrm{R}}$. Total DNA (including chromosomal DNA and phage DNA) was extracted at successive time points following infection of $S$. pneumoniae $\mathrm{R} 6-\mathrm{SOCP} \mathrm{R}^{\mathrm{R}}$ and $\mathrm{R} 6-\mathrm{DP} 1^{\mathrm{R}}$ with phages SOCP and $\mathrm{Dp}-1$, respectively. The DNA samples were then digested with SspI before being electrophoresed and transferred on Nylon membrane. Hybridizing membranes with probes covering the holin gene from SOCP or Dp-1 allowed monitoring the kinetics of phage genome replication by measuring the intensity of phage DNA over time after infection. In S. pneumoniae $\mathrm{R} 6$, replication of SOCP was already well advanced at 15 min following infection and SOCP DNA levels had increased by an estimated 20-fold after 90 min (Fig. 3a and f). In contrast, no holin-derived signals could be detected following infection of R6$\mathrm{SOCP}^{\mathrm{R}}$ even at the $90 \mathrm{~min}$ time point (Fig. $3 \mathrm{~b}$ and $\mathrm{f}$ ). This suggests that resistance in S. pneumoniae R6$\mathrm{SOCP}^{\mathrm{R}}$ occurs at very early stages of the infection cycle. In our experimental conditions, the replication of pneumophage Dp-1 within $S$. pneumoniae R6 began after a latency of about 30 to $45 \mathrm{~min}$ [29], and after 90 min Dp-1 DNA levels had increased by an estimated 22-fold (Fig. 4a and c). An increase in Dp-1 holin signals was also observed upon infection of $S$. pneumoniae $\mathrm{R} 6-\mathrm{DP} 1^{\mathrm{R}}$ but at a 4 -fold decreased rate compared to S. pneumoniae R6 (Fig. 4b-c). This suggests that Dp-1 replication occurred but was severely impaired in the $\mathrm{R} 6-\mathrm{DP} 1^{\mathrm{R}}$ mutant.

\section{Whole genome sequencing of S. pneumoniae R6-SOCP ${ }^{R}$ and R6-DP1 ${ }^{\mathrm{R}}$}

Whole genome sequencing is useful for identifying genes involved in host-phage interactions [30-32] and the genomes of S. pneumoniae R6-SOCP ${ }^{\mathrm{R}}$ and R6$\mathrm{DP} 1^{\mathrm{R}}$ (one clone of each) were sequenced to identify mutations putatively implicated in resistance. Wholegenome sequencing revealed a total of eleven and five nucleotide mutations in the genomes of $\mathrm{R} 6-\mathrm{SOCP}^{\mathrm{R}}$ and $R 6-D P 1^{R}$, respectively (Table 2 ). None of the mutations (or mutated genes) was common to both mutants (Table 2) which is consistent with the absence of cross-resistance (Table 1). Every mutation detected in R6-SOCP ${ }^{\mathrm{R}}$ occurred within coding sequences (in eight genes) while two of those found in $\mathrm{R} 6-\mathrm{DP} 1^{\mathrm{R}}$ were non-coding (Table 2). For both mutants, mutations in open reading frames invariably led to amino acid substitutions (Table 2).

The role of each mutation in pneumophage resistance was assessed by resistance construction, a strategy shown useful for pinpointing mutations implicated in antibiotic resistance in S. pneumoniae [33-39]. This was done by transforming S. pneumoniae R6 WT with separate PCR products covering variant alleles derived from $\mathrm{R} 6-\mathrm{SOCP}^{\mathrm{R}}$ or R6-DP1 ${ }^{\mathrm{R}}$ along with a PCR fragment covering the $r p s L$ allele of S. pneumoniae CP1250 [40] and conferring
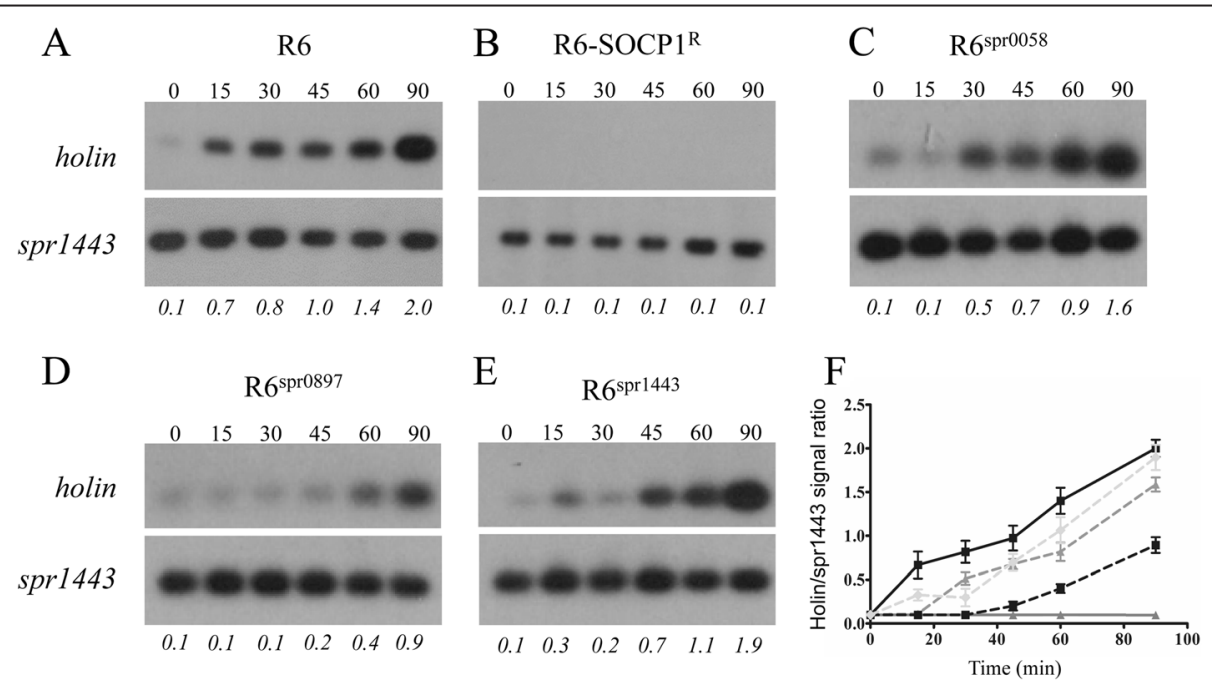

Fig. 3 Kinetics of SOCP DNA replication. S. pneumoniae R6 WT (a), R6-SOCPR (b) and S. pneumoniae R6 transformed with R6-SOCPR-derived alleles for genes spr0058 (c), spr0897 (d) or spr1443 (e) were infected with the lytic phage SOCP at a MOI of 0.1. Total DNA was extracted at baseline and at 15, 30, 45, 60 and 90 min after infection. Total DNA was digested with Sspl before being hybridized with an [a- ${ }^{32}$ P]dCTP-labeled probe covering the holin gene of SOCP (top blots). DNA loading was controlled by hybridizing the blots with an [a- ${ }^{32}$ P] dCTP-labeled probe covering the spr1443 gene from S. pneumoniae R6 (bottom blots). Holin/spr1443 signal ratios are indicated in italics below the blots. Hybridizations were done in triplicates and representative blots are shown. $\mathbf{f}$ Plot of holin/spr1443 signal ratios for S. pneumoniae R6 WT (black), R6-SOCPR (dark grey), R6 $6^{\text {spr0058 }}$ (dashed dark grey), R6 ${ }^{\text {spro897 }}$ (dashed black), and R6 ${ }^{\text {spr1443 }}$ (dashed light grey). For each strain, the ratios at each time point (except for $\mathrm{R}^{\mathrm{spr} 1443}$ at $\left.90 \mathrm{~min}\right)$ were significantly different $(p<0.01$ by two-way ANOVA) than those of R6 WT 

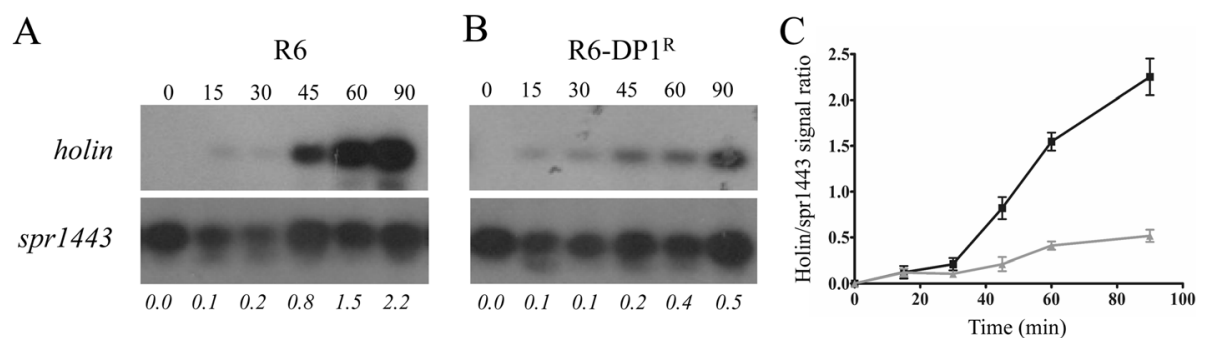

Fig. 4 Kinetics of Dp-1 DNA replication. S. pneumoniae R6 WT (a) and R6-DP1 ${ }^{R}$ (b) were infected with the lytic phage Dp-1 at a MOI of 0.1. Total DNA was extracted at baseline and at 15, 30, 45, 60 and 90 min after infection. Total DNA was digested with Sspl before being hybridized with an $\left[\mathrm{a}^{3}{ }^{32} \mathrm{P}\right] \mathrm{dCTP}$-labeled probe covering the holin gene of DP-1. DNA loading was controlled by hybridizing the blots with an [a- $\left.{ }^{32} \mathrm{P}\right] \mathrm{dCTP}-\mathrm{labeled}$ probe covering the spr1443 gene from S. pneumoniae R6. Holin/spr1443 signal ratios are indicated in italics below the blots. Hybridizations were done in triplicates and representative blots are shown. c Plot of holin/spr1443 signal ratios for S. pneumoniae R6 WT (black) and R6-DP1 ${ }^{R}$ (dark grey). The R6-DP1 ${ }^{\mathrm{R}}$ ratios from 45 to $90 \mathrm{~min}$ were significantly different $(p<0.001$ by two-way ANOVA) than those of R6 WT

Table 2 List of all mutations identified in the genome of R6-SOCP ${ }^{R}$ and R6-DP1 ${ }^{R}$

\begin{tabular}{|c|c|c|c|c|}
\hline \multirow{2}{*}{$\frac{\text { Strains }}{\text { R6-SOCPR }}$} & \multirow{2}{*}{$\begin{array}{l}\text { Genes } \\
\text { spr0058 }\end{array}$} & \multirow{2}{*}{$\begin{array}{l}\text { Function } \\
\text { GntR-type transcription factor }\end{array}$} & \multicolumn{2}{|c|}{ Mutations ${ }^{a, b, c}$} \\
\hline & & & \multicolumn{2}{|c|}{ G460A } \\
\hline & & & \multicolumn{2}{|l|}{ E154K } \\
\hline & \multirow[t]{2}{*}{ spr0093 } & \multirow[t]{2}{*}{ Phosphoglycolate phosphatase } & \multicolumn{2}{|l|}{ G343T } \\
\hline & & & \multicolumn{2}{|l|}{ D115Y } \\
\hline & \multirow[t]{2}{*}{ spr0897 } & \multirow{2}{*}{$\begin{array}{l}\text { Glycerophosphoryl diester } \\
\text { phosphodiesterase }\end{array}$} & \multicolumn{2}{|l|}{ C484A } \\
\hline & & & \multicolumn{2}{|l|}{ P162T } \\
\hline & \multirow[t]{3}{*}{ spr1191 } & \multirow{3}{*}{$\begin{array}{l}\text { ABC protein - ATP binding } \\
\text { domain }\end{array}$} & \multicolumn{2}{|l|}{$\mathrm{G} 1624 \mathrm{~T}^{\mathrm{d}}$} \\
\hline & & & $\mathrm{T} 1625 \mathrm{G}^{\mathrm{d}}$ & G1629T \\
\hline & & & V542C & L543F \\
\hline & srp1443 & Mur ligase homolog & \multicolumn{2}{|l|}{$\mathrm{T} 1223 \mathrm{C}$} \\
\hline & & & \multicolumn{2}{|l|}{$V 408 A$} \\
\hline & spr1584 & Hypothetical protein & \multicolumn{2}{|l|}{$\mathrm{A} 1229 \mathrm{C}$} \\
\hline & & & \multicolumn{2}{|l|}{ Y410S } \\
\hline & spr1777 & RNA polymerase rpoB & \multicolumn{2}{|l|}{ G827C } \\
\hline & & & \multicolumn{2}{|l|}{$R 276 P$} \\
\hline & \multirow[t]{2}{*}{ spr1923 } & \multirow[t]{2}{*}{ Hypothetical protein } & G690C & G691C \\
\hline & & & Q230H & A231P \\
\hline \multirow[t]{7}{*}{$\mathrm{R} 6-\mathrm{DP} 1^{\mathrm{R}}$} & spr0291 & $\begin{array}{l}\text { Phosphotransferase system } \\
\text { sugar-specific Ell component }\end{array}$ & \multicolumn{2}{|l|}{ C-101G } \\
\hline & spr1130 & McrB subunit of McrBC & \multicolumn{2}{|l|}{ T985G $^{\mathrm{d}}$} \\
\hline & & & \multicolumn{2}{|l|}{ G986C $C^{d}$} \\
\hline & & & \multicolumn{2}{|l|}{ C329A } \\
\hline & spr1445 & Dipeptidase M24 family & \multicolumn{2}{|l|}{ G918A } \\
\hline & & & \multicolumn{2}{|l|}{ M3061 } \\
\hline & spr1453 & Major facilitator transporter & \multicolumn{2}{|l|}{$\mathrm{T}-187 \mathrm{G}$} \\
\hline
\end{tabular}

${ }^{a}$ For each mutation, the change at the nucleotide level is indicated on top and the corresponding substitution at the amino acid level is indicated in italic underneath

${ }^{\mathrm{b}}$ Mutations in bold have a confirmed role in resistance

${ }^{\mathrm{c}}$ For mutations in intergenic regions, an hyphen in front of the mutated position indicates the nucleotide position upstream of the ATG

${ }^{d}$ Both mutated positions are part of the same codon and lead to a single amino acid substitution resistance to streptomycin. The latter was used as a surrogate marker for the selection of transformants. The rpsL allele had no impact on pneumophage susceptibility levels when transformed alone (Tables 3 and 4). The streptomycin-resistant transformants were then screened for the presence of mutated alleles. Using a similar approach, the mutated genes were reverted back to their WT versions in the R6$\mathrm{SOCP}^{\mathrm{R}}$ or R6-DP1 ${ }^{\mathrm{R}}$ mutants for phenotype confirmation. Finally, each reconstructed strain was tested for resistance to SOCP or Dp-1.

\section{Mutations involved in resistance to SOCP}

A role in resistance to phage SOCP was confirmed for three of the eleven mutations (in genes spr0058, spr0897 and spr1443) detected in the S. pneumoniae R6-SOCP ${ }^{\mathrm{R}}$ mutant (Table 3). The gene spr0058 codes for a GntRtype transcription factor and the introduction of the spr0058 allele from R6-SOCP ${ }^{\mathrm{R}}$ into $S$. pneumoniae R6 WT decreased the EOP of SOCP by three orders of magnitude (R6 ${ }^{\mathrm{spr} 0058}$ in Table 3). Transforming S. pneumoniae R6 WT with PCR fragments covering the genes spr0897 (coding for a glycerophosphoryl phosphodiesterase) or spr1443 (coding for a Mur ligase homolog) amplified from S. pneumoniae $\mathrm{R} 6-\mathrm{SOCP} \mathrm{R}^{\mathrm{R}}$ similarly decreased the EOP of SOCP by three logs $\left(\mathrm{R}^{\mathrm{spr} 0897}\right.$ and $\mathrm{R}^{\mathrm{spr} 1443}$ in Table 3). In all cases, reverting any of the three mutations in S. pneumoniae R6-SOCP ${ }^{\mathrm{R}}$ to a WT allele conferred coherent sensitivity levels to phage SOCP for the transformants R6-SOCP ${ }^{\mathrm{R} \_s p r 0058 W T}$, R6-SOCP ${ }^{\mathrm{R} \_s p r 0897 W T}$ and R6-SOCP ${ }^{\mathrm{R} \text { spr1443WT }}$ (Table 3). Moreover, introducing the spr0058, spr0897 and spr1443 mutations altogether in S. pneumoniae R6 produced transformants as resistant to SOCP as the original R6-SOCP ${ }^{\mathrm{R}}$ mutant ( $\mathrm{R}^{\text {spro058-0897-1443 }}$ in Table 3), although the combination of any two mutations appears sufficient to confer highlevel resistance (Table 3). Interestingly, introducing the spr0058, spr0897 or spr1443 mutations in S. pneumoniae 
Table 3 The role of mutations detected in $\mathrm{R} 6-\mathrm{SOCP} \mathrm{P}^{\mathrm{R}}$ in resistance to phage SOCP

\begin{tabular}{|c|c|c|c|c|c|c|c|c|c|}
\hline \multirow[t]{2}{*}{ Strains $^{a}$} & \multicolumn{8}{|l|}{ Alleles $^{\mathrm{b}}$} & \multirow{2}{*}{$\begin{array}{l}\text { EOPC }^{C} \\
(\mathrm{SOCP})\end{array}$} \\
\hline & spr0058 & spr0093 & spr0897 & spr1191 & srp1443 & spr1584 & spr1777 & spr1923 & \\
\hline R6 & WT & WT & WT & WT & WT & WT & WT & WT & 1 \\
\hline$R 6^{\mathrm{smR}}$ & WT & WT & WT & WT & WT & WT & WT & WT & 1 \\
\hline $\mathrm{R} 6-\mathrm{SOCP}{ }^{\mathrm{R}}$ & $R$ & $R$ & $R$ & $R$ & $\mathrm{R}$ & $\mathrm{R}$ & $\mathrm{R}$ & $\mathrm{R}$ & $10^{-9}$ \\
\hline$R 6^{\text {spro058 }}$ & $\mathrm{R}$ & WT & WT & WT & WT & WT & WT & WT & $10^{-3}$ \\
\hline $\mathrm{R}^{\Delta \mathrm{spr} 0058}$ & none ${ }^{d}$ & WT & WT & WT & WT & WT & WT & WT & $10^{-3}$ \\
\hline$R 6^{\text {spro093 }}$ & WT & $\mathrm{R}$ & WT & WT & WT & WT & WT & WT & 1 \\
\hline$R 6^{\text {spr0897 }}$ & WT & WT & R & WT & WT & WT & WT & WT & $10^{-3}$ \\
\hline$R 6^{\mathrm{spr} 1191}$ & WT & WT & WT & $\mathrm{R}$ & WT & WT & WT & WT & 1 \\
\hline$R 6^{\text {spr1443 }}$ & WT & WT & WT & WT & $\mathrm{R}$ & WT & WT & WT & $10^{-3}$ \\
\hline $\mathrm{R}^{\mathrm{spr} 1584}$ & WT & WT & WT & WT & WT & $\mathrm{R}$ & WT & WT & 1 \\
\hline$R 6^{\text {spr1777 }}$ & WT & WT & WT & WT & WT & WT & $\mathrm{R}$ & WT & 1 \\
\hline $\mathrm{R}^{\mathrm{spr} 1923}$ & WT & WT & WT & WT & WT & WT & WT & $\mathrm{R}$ & 1 \\
\hline $\mathrm{R}^{\text {spro058-0897 }}$ & $\mathrm{R}$ & WT & $\mathrm{R}$ & WT & WT & WT & WT & WT & $10^{-9}$ \\
\hline $\mathrm{R}^{\text {spro058-1443 }}$ & $\mathrm{R}$ & WT & WT & WT & $R$ & WT & WT & WT & $10^{-9}$ \\
\hline $\mathrm{R}^{\mathrm{spr} 0897-1443}$ & WT & WT & $\mathrm{R}$ & WT & $\mathrm{R}$ & WT & WT & WT & $10^{-9}$ \\
\hline$R^{\text {spro058-0897-1443 }}$ & R & WT & $\mathrm{R}$ & WT & $\mathrm{R}$ & WT & WT & WT & $10^{-9}$ \\
\hline R6-SOCP R_spro058WT & WT & $\mathrm{R}$ & $\mathrm{R}$ & $\mathrm{R}$ & $\mathrm{R}$ & $\mathrm{R}$ & $\mathrm{R}$ & $\mathrm{R}$ & $10^{-6}$ \\
\hline R6-SOCPR_sproo93WT & $\mathrm{R}$ & WT & $\mathrm{R}$ & R & $\mathrm{R}$ & $\mathrm{R}$ & $\mathrm{R}$ & $\mathrm{R}$ & 1 \\
\hline R6-SOCP_spro897WT & R & R & WT & R & $\mathrm{R}$ & $\mathrm{R}$ & $\mathrm{R}$ & $\mathrm{R}$ & $10^{-6}$ \\
\hline R6-SOCPR_spr1191WT & R & $\mathrm{R}$ & $\mathrm{R}$ & WT & $\mathrm{R}$ & $\mathrm{R}$ & $\mathrm{R}$ & $\mathrm{R}$ & 1 \\
\hline R6-SOCPR_spr1443WT & R & $\mathrm{R}$ & R & $\mathrm{R}$ & WT & $\mathrm{R}$ & $\mathrm{R}$ & $\mathrm{R}$ & $10^{-6}$ \\
\hline R6-SOCPR_spr1584WT & $\mathrm{R}$ & $\mathrm{R}$ & $\mathrm{R}$ & $\mathrm{R}$ & $\mathrm{R}$ & WT & $\mathrm{R}$ & $\mathrm{R}$ & 1 \\
\hline R6-SOCPR_spr1777WT & R & R & R & R & $\mathrm{R}$ & $\mathrm{R}$ & WT & $\mathrm{R}$ & 1 \\
\hline R6-SOCPR_spr1923WT & $R$ & $\mathrm{R}$ & $\mathrm{R}$ & $\mathrm{R}$ & $\mathrm{R}$ & $\mathrm{R}$ & $\mathrm{R}$ & WT & 1 \\
\hline
\end{tabular}

R6 WT also impaired the DNA replication of SOCP (Fig. 3c-f), especially in the case of spr0897 (Fig. 3f).

When additional $S$. pneumoniae $\mathrm{R} 6$ mutants made resistant to SOCP were tested for the presence of mutations in spr0058, spr1897 and spr1443, three (out of four) additional mutants had a mutation in at least one of the genes (Table 5). None of the mutants had the exact same genotype for the three genes tested which preclude multiple sampling of the same end-point clone from the original culture (although divergence from a common ancestor mutated for spr1443 cannot be excluded) (Table 5). Instead, it highlights the major role of genes on the infective cycle of SOCP. For spr0897 and spr1443 the mutations even targeted the same amino acid as in the R6-SOCP ${ }^{\mathrm{R}}$ mutant, leading to a different substitution in the case of spr0897 (Table 5). S. pneumoniae R6SOCP $-5^{\mathrm{R}}$ was the only additional mutant with a mutation in gene spr0058, harbouring a non-sense mutation at codon 131 (Table 5). The E154K mutation originally detected in spr0058 in R6-SOCP ${ }^{\mathrm{R}}$ (Table 2) is also expected to considerably alter the activity of the protein given that S. pneumoniae $\mathrm{R}^{\mathrm{spr} 0058}$ harbouring the spr0058 E154K mutation from R6-SOCP ${ }^{\mathrm{R}}$ displayed the same level of resistance to SOCP than $S$. pneumoniae $\mathrm{R}^{\Delta \mathrm{spr0058}}$ in which we inactivated spr0058 by insertion-duplication mutagenesis (Table 3). The gene product of spr0058 has similarity with regulators of the metabolite-responsive GntR family, which often regulate the expression of genes nearby of their location on the chromosome [41]. Comparative gene expression profiling by RNAseq between S. pneumoniae R6 WT and $S$. pneumoniae $\mathrm{R}^{\Delta \mathrm{spr0058}}$ (Additional file 3 ) indeed revealed that an adjacent operon on the chromosome (spr0059spr0065) coding for sugar transporters and metabolizing enzymes is overexpressed upon inactivation of spr0058 (Additional file 4). Additional putative operons also had 
Table 4 The role of mutations detected in $\mathrm{R} 6-\mathrm{DP} 1^{\mathrm{R}}$ in resistance to phage Dp-1

\begin{tabular}{|c|c|c|c|c|c|}
\hline \multirow[t]{2}{*}{ Strains $^{a}$} & \multicolumn{4}{|l|}{ Alleles $^{b}$} & \multirow{2}{*}{$\begin{array}{l}\mathrm{EOP}^{\mathrm{C}} \\
(\mathrm{Dp}-1)\end{array}$} \\
\hline & spr0290 & spr1130 & spr1445 & spr1453 & \\
\hline$\overline{R 6}$ & WT & WT & WT & WT & 1 \\
\hline$R 6^{\mathrm{smR}}$ & WT & WT & WT & WT & 1 \\
\hline R6-DP1 ${ }^{R}$ & $\mathrm{R}$ & $\mathrm{R}$ & $\mathrm{R}$ & $\mathrm{R}$ & $10^{-8}$ \\
\hline$R 6^{\mathrm{spr} 1130}$ & WT & $\mathrm{R}$ & WT & WT & $10^{-8}$ \\
\hline$R 6^{\mathrm{spr} 1445}$ & WT & WT & $R$ & WT & 1 \\
\hline R6-DP1 ${ }^{\text {R_spr1130WT }}$ & R & WT & $\mathrm{R}$ & $R$ & 1 \\
\hline
\end{tabular}

${ }^{\mathrm{a}} \mathrm{R} 6^{\mathrm{smR}}$ integrated an $r p s L$ allele conferring resistance to streptomycin (smR). Each mutated and WT alleles presented in the table was co-transformed with this rpsL allele that was used as a surrogate marker for the selection of transformants (see Methods). Although not indicated, every transformants in Table 4 are $s m R$

${ }^{b}$ WT, S. pneumoniae R6 WT gene sequence; R, S. pneumoniae R6-DP1 ${ }^{R}$ gene sequence

${ }^{C} E O P$, efficiency of plaquing. Represents the ratio of phage titers from the test strain to the indicator strain R6 WT. Measured from three independent triplicate

their expression altered in S. pneumoniae $\mathrm{R}^{\Delta \mathrm{spr} 0058}$, including several carbohydrate transport systems, which are also likely part of the spr0058 regulon (Additional file 4).

\section{Mutations involved in resistance to $\mathrm{Dp}-1$}

Whole genome sequencing of S. pneumoniae R6-DP1 ${ }^{\mathrm{R}}$ revealed a total of five mutations, three of which occurred within open reading frames (Table 2). Resistance reconstruction further confirmed two nucleotide mutations targeting the same codon and leading to a single amino acid substitution in the McrB subunit of the McrBC restriction endonuclease (spr1130) (Table 2) were solely responsible for the high-level resistance of R6-DP $1^{\mathrm{R}}$ (Table 4). Indeed, pneumophage Dp-1 had the same EOP on R6-DP $1^{\mathrm{R}}$ than on $S$. pneumoniae $\mathrm{R} 6^{\mathrm{spr} 1130}$, a S. pneumoniae R6 WT derivative into which a spr1130 PCR fragment amplified from $\mathrm{R} 6-\mathrm{DP} 1^{\mathrm{R}}$ was introduced (Table 4). Conversely, reverting spr1130 to a WT version in $\mathrm{R} 6-\mathrm{DP} 1^{\mathrm{R}}$ completely abrogated its resistance against pneumophage Dp-1 (R6-DP1 ${ }^{\text {R_spr1130WT }}$ in Table 4), confirming the role of the mutation in the phage resistance phenotype. Testing for additional S. pneumoniae R6 mutants made resistant to $\mathrm{Dp}-1$ again revealed that three out of the four additional mutants had the same mutation as $\mathrm{R} 6-\mathrm{DP} 1^{\mathrm{R}}$ (Table 5), although this time we cannot exclude that the same clone had been selected multiple times from the original culture.

\section{Discussion and conclusion}

Bacteria have evolved diverse antiviral strategies to survive in phage-containing environments. These include adsorption resistance, which results in reduced interactions between the phage and its bacterium host; restrictionmodification mechanisms and CRISPR-Cas systems, where bacteria survive and phage genomes are cleaved;
Table 5 Targeted screening for mutations in additional bacteriophage insensitive mutants

\begin{tabular}{|c|c|c|c|c|}
\hline \multirow[t]{2}{*}{ Strains $^{a}$} & \multicolumn{4}{|l|}{ Alleles $^{\mathrm{b}, \mathrm{c}}$} \\
\hline & spr0058 & spr0897 & spr1130 & spr1443 \\
\hline \multirow[t]{2}{*}{ R6-SOCP } & G460A & C484A & NA & T1223C \\
\hline & E154K & P162T & & V408A \\
\hline R6-SOCP- $2^{R}$ & no mutation & no mutation & NA & no mutation \\
\hline \multirow[t]{2}{*}{$\mathrm{R} 6-\mathrm{SOCP}-3^{\mathrm{R}}$} & no mutation & C485T & NA & T1223C \\
\hline & & P162L & & V408A \\
\hline \multirow[t]{2}{*}{$\mathrm{R} 6-\mathrm{SOCP}-4^{\mathrm{R}}$} & C393A & no mutation & NA & T1223C \\
\hline & stop & & & V408A \\
\hline \multirow[t]{2}{*}{ R6-SOCP-5 $5^{R}$} & no mutation & no mutation & NA & $\mathrm{T} 1223 \mathrm{C}$ \\
\hline & & & & V408A \\
\hline \multirow[t]{3}{*}{$\mathrm{R} 6-\mathrm{DP} 1^{\mathrm{R}}$} & NA & NA & T985G $\mathrm{G}^{\mathrm{d}}$ & NA \\
\hline & & & G986C ${ }^{d}$ & \\
\hline & & & C $329 A$ & \\
\hline \multirow[t]{3}{*}{ R6-DP1-2 ${ }^{R}$} & NA & NA & T985G $\mathrm{G}^{\mathrm{d}}$ & NA \\
\hline & & & $\mathrm{G} 986 \mathrm{C}^{\mathrm{d}}$ & \\
\hline & & & C329A & \\
\hline \multirow[t]{3}{*}{ R6-DP1-3 ${ }^{R}$} & NA & NA & T985G $\mathrm{G}^{\mathrm{d}}$ & NA \\
\hline & & & G986C ${ }^{d}$ & \\
\hline & & & C $329 A$ & \\
\hline R6-DP1-4 & NA & NA & no mutation & NA \\
\hline \multirow[t]{3}{*}{ R6-DP1-5 ${ }^{R}$} & NA & NA & T985G $\mathrm{G}^{\mathrm{d}}$ & NA \\
\hline & & & G986C $C^{d}$ & \\
\hline & & & C329A & \\
\hline
\end{tabular}

${ }^{a}$ Five different mutants had initially been obtained from the same $S$. pneumoniae R6 parental culture for the selection of mutants insensitive to the phages SOCP or Dp-1

${ }^{\mathrm{b}}$ For each mutation, the change at the nucleotide level is indicated on top and the corresponding substitution at the amino acid level is indicated in italic underneath

${ }^{c} \mathrm{NA}$, not applicable. These alleles were not sequenced because they should be irrelevant to the resistance phenotype of the phage

${ }^{d}$ Both mutated positions are part of the same codon and lead to a single amino acid substitution

and abortive infections, where bacteria die and phages usually remain trapped inside (reviewed in [42]). Also, many steps of the phage replication cycle likely depend on bacterial gene products, which if mutated may lead to phage resistance. Additional phage defence systems include superinfection exclusion whereby immunity occurs through the expression of a protein blocking the entry of DNA for specific phages. The genes encoding these proteins are often found in prophages, suggesting that in many cases these systems are important for phage-phage interactions rather than phage-host interactions (reviewed in [42]).

The genomic characterization of a $S$. pneumoniae R6 mutant insensitive to phage SOCP revealed mutations in genes spr0058, spr0897 and spr1443 that seemingly work additively to increase resistance. The gene spr0058 is 
coding for a transcriptional regulator of the GntR family and suffered from a G460A mutation leading to an E154K substitution in S. pneumoniae R6-SOCP ${ }^{\mathrm{R}}$ (Table 2). GntR regulators are one of the most abundant and widely distributed groups of helix-turn-helix transcription factors [41]. They contain a DNA-binding domain at their Nterminus as well as an effector-binding and oligomerisation domain at the $\mathrm{C}$-terminus of the protein in which the E154K mutation is located. The effector-binding domain is believed to modulate activity of bacterial transcription factors in response to binding small molecules [43]. The inactivation of spr0058 in $\mathrm{R}^{\Delta \text { spro058 }}$ conferred the same SOCP resistance phenotype as the E154K mutation alone (Table 3) and it is tempting to speculate that the activity of the GntR regulator is also greatly impaired in the R6$\mathrm{SOCP}^{\mathrm{R}}$ mutant. Inactivation of GntR regulators through the acquisition of mutations was similarly shown to occur during adaption of Comamonas testosteroni to utilize phenol as the major carbon source, whereby several different missense mutations inactivated the repressor activity of the GntR regulator AphS [44]. GntR regulators bind DNA as dimers through interaction between their C-terminal domain [45] and one possibility is that the spr0058 mutation in $\mathrm{R} 6-\mathrm{SOCP}^{\mathrm{R}}$ prevents repression by impairing with dimerization of the regulator at the operator-binding site. Another possibility would be that the mutation locks the repressor in a conformation mimicking the presence of bond ligand, thereby alleviating repression.

GntR family regulators often regulate (e.g. repress) the expression of neighbor genes [41] and the increased expression in $\mathrm{R}^{\Delta \mathrm{spr} 0058}$ of adjacent genes spr0059-65 coding for sugar transporters and metabolizing enzymes is consistent with this assumption. Bacterial operons coding for carbohydrate transporters constitute functional units and, in addition to the transporter, they are usually coding for glycosylhydrolases for the production of mono- or disaccharides and/or enzymes for the metabolic steps linking specific sugars to glycolysis [46]. In the case of the spr005965 operon overexpressed in $\mathrm{R}^{\Delta \mathrm{spr} 0058}$ (Additional file 4), the beta-galactosidase encoded by spr0059 was characterized as a surface enzyme responsible for cleavage of Galß1-3GlcNac $[47,48]$ and it was proposed that the operon may thus code for a galactose uptake system [46]. Increased content of galactose in cell wall polymers have been correlated with increased bacteriophage resistance in Lactococcus lactis subsp. cremoris [49] and Rhizobium meliloti $[50,51]$. In the case of phage-resistant $L$. lactis subsp. cremoris, an increase in galactosyl-containing lipoteichoic acid in the cell wall was further linked to a reduced bacteriophage adsorption [52]. Teichoic acid is also involved in pneumophage adsorption [53] and a similar phenomenon could possibly explain the reduced adsorption of SOCP on S. pneumoniae R6-SOCP ${ }^{\mathrm{R}}$. The expression of many other genes (and operons) was altered in $\mathrm{R} 6^{\Delta \mathrm{spr} 0058}$ besides spr0059-65 however (Additional file 4), and pinpointing the gene(s) actually implicated in resistance to SOCP will required further investigation.

The gene spr0897 mutated in $\mathrm{R}-\mathrm{SOCP}^{\mathrm{R}}$ (Table 2) codes for a plasma membrane glycerophosphoryl diester phosphodiesterase (EC 3.1.4.46), an enzyme of the glycerophospholipid metabolism pathway involved in the production of glycerol-3-phosphate along with choline or ethanolamine from glycerophosphocholine or glycerophosphoethanolamine, respectively [54]. The P162T substitution in $\mathrm{R} 6-\mathrm{SOCP}^{\mathrm{R}}$ is located at a conserved position within the second extracellular loop based on TMHMM transmembrane domains prediction. Most studies on glycerophosphoryl diester phosphodiesterases have focused on the catalytic domain which is located away from the P162T mutation at the C-terminus of the protein and the role of the mutation on the activity of the protein remains to be further explored. Given the role of these enzymes in the production of choline [55] and the dependency of pneumophage adsorption on choline-containing teichoic acid in the bacterial cell wall [53], it is possible that the mutation either interferes with the function of the protein or that it is favoring glycerophosphoethanolamine over glycerophosphocholine as its preferred substrate. In both cases this would translate into a decreased choline content (and also most likely of choline-binding proteins) in the cell wall, possibly explaining the decreased adsorption of SOCP on R6-SOCP ${ }^{\mathrm{R}}$ (Fig. 2). However, glycerophosphoryl diester phosphodiesterases have been shown to influence gene expression [56] and an indirect role for the mutation in resistance by altering gene expression in $\mathrm{R} 6-\mathrm{SOCP}^{\mathrm{R}}$ cannot be ruled out.

The last mutation implicated in resistance against bacteriophage SOCP in $\mathrm{R} 6-\mathrm{SOCP}^{\mathrm{R}}$ occurred in gene spr1443 (Table 2) coding for a Mur ligase homolog named MurT [57-59]. MurT, along with the product of gene spr1444 (GatD), was recently shown to be responsible for the amidation of the glutamate residue in position 2 of the stem peptide of lipid II, a peptidoglycan precursor [57-59]. Amidation of lipid II is required for efficient peptidoglycan cross-linking in some Gram positive bacteria, including $S$. pneumoniae, and non-amidated glutamate-containing peptides were indeed found to be scarce in S. pneumoniae [60]. Cell wall cross-linking is important for optimal growth and influences susceptibility to antibiotics and murein hydrolases $[57,58]$. The MurT V408A substitution detected in $\mathrm{R} 6-\mathrm{SOCP}^{\mathrm{R}}$ is located at the C-terminus of the protein in a domain named DUF1727. This domain of unknown function is associated with the C-terminus of bacterial Mur ligases (http://pfam.xfam.org/family/PF08353). The role of the V408A substitution on the activity of MurT/GatD remains to be established but is unlikely to 
inactivate the activity of this amido transferase system which was shown to be essential in S. aureus $[57,58]$ and S. pneumoniae R6 [59].

Resistance to bacteriophage Dp-1 involved a single mutation in the gene spr1130 coding for the McrB subunit of a type IV McrBC restriction endonuclease (Tables 2 and 5). Type IV restriction endonucleases recognize modified, typically methylated, DNA. The McrBC endonucleases recognize and cleave DNA containing two hemi or fully methylated $\mathrm{R}^{\mathrm{m}} \mathrm{C}$ sites in an optimal distance of about 40 to 80 base pairs [61]. The nuclease active site of the McrBC restriction endonuclease resides in its $\mathrm{McrC}$ subunit [62] while McrB is responsible for DNA binding and GTP hydrolysis $[63,64]$. The C330A mutation in $R 6-D P 1^{R}$ is not in the McrB domain responsible for recognition of methylated DNA which was shown to reside in the first 161 residues of the protein $[65,66]$. The mutation is instead located in the GTPase domain located at the C-terminus of $\mathrm{McrB}$, in a region conserved between several McrB sequences [67]. Interestingly, targeted mutagenesis of conserved polar amino acids to an alanine residue within the conserved region in Escherichia coli translated into an array of phenotypes going from complete inactivation to impaired GTP or DNA binding and even enhanced GTPase activity [67]. The equivalent residue to $\mathrm{C} 330$ in $\mathrm{R} 6-\mathrm{DP} 1^{\mathrm{R}}$ was not part of the sites targeted by the mutagenesis however and it is not possible to infer about a possible phenotype at the moment. Still, the Dp- 1 genome is resistant to several type II restriction enzymes, suggesting the presence of modified bases, and it will be interesting to further study the impact of the mutated version of McrBC on Dp-1 DNA.

Finally, every lytic pneumophage studied to date (the omega phages in [27] and the SOCP and Dp-1 phages herein) are inhibited by the pneumococcal capsule and it is puzzling how these phages can thrive in natural settings among encapsulated clinical isolates. Many encapsulated pneumococcal strains also carry prophages and were thus infected by phages at some point [19-21]. On the other hand, pneumococcal strains that lack a capsule have been isolated from conjunctivitis cases [68]. The conversion between encapsulated and unencapsulated states is not uncommon in S. pneumoniae however and may be an important factor in population dynamics [69] and favor phage infection. Alternatively, the nasopharynx is host to the related Streptococcus mitis which was shown to support the replication of pneumophages, at least in the case of SOCP and Dp-1 [25]. Interestingly, non-typeable strains of $S$. pneumoniae (which include those lacking a capsule) were shown to have significantly higher probabilities to act as DNA donor in DNA recombination events compared to strains with well- defined capsule types [70]. Whether this is due to phage-mediated lysis is not known but it is worrying that non-typeable strains of S. pneumoniae also appear to be highly enriched in antibiotic resistance alleles [71]. It might thus be worth assessing whether sensitivity to lytic phages makes unencapsulated (non-typeable) strains a potential major reservoir to enhance the flow of resistance genes.

In conclusion, this study reported on the use of whole genome sequencing to expedite the identification of novel pneumococcal genes involved in phage-host interactions. It also suggested that different host factors are involved in the replication of phages belonging to different phage families.

\section{Methods}

Amplification, phage titer and adsorption of SOCP and Dp-1 Pneumophages SOCP [25] and Dp-1 [12] were obtained from the Félix d'Hérelle Reference Center for Bacterial Viruses (www.phage.ulaval.ca). Amplification and purification of bacteriophages was done on $S$. pneumoniae R6 WT as previously described for SOCP [25] and Dp-1 [23]. Phage titers were determined on S. pneumoniae grown in filtrated $\mathrm{BHI}+$ (BHI medium supplemented with $0.25 \mathrm{mM} \mathrm{CaCl}, 0.2 \mathrm{mM} \mathrm{MgCl}_{2}$, $8.0 \mu \mathrm{M} \mathrm{MnCl}, 5 \mathrm{ng} / \mathrm{mL}$ of choline chloride and 50 $\mathrm{mM}$ Tris $\mathrm{pH} 7.5$ ) at $35{ }^{\circ} \mathrm{C}$ in a $5 \% \mathrm{CO}_{2}$ atmosphere. When cell growth reached an $\mathrm{OD}_{600}$ of 0.12 a volume of $2 \mathrm{~mL}$ was taken and spread on agarose plates prepared by mixing equal volumes of $1 \%$ agarose and $2 \times$ filtrated BHI+ supplemented with $50 \mu \mathrm{g} \mathrm{ml}^{-1}$ catalase and $0.4 \%$ of glycine. Plates were left to stand for $5 \mathrm{~min}$ before the excess liquid was drained and left to dry for $10 \mathrm{~min}$. Purified SOCP and Dp-1 were serially diluted in BHI and $5 \mu \mathrm{L}$ was spotted on the bacterial top and left to dry for $10 \mathrm{~min}$. The plates were incubated overnight at $35{ }^{\circ} \mathrm{C}$ under a $5 \% \mathrm{CO}_{2}$ atmosphere. Plaques were counted, and the phage titer was determined. EOP was calculated by dividing the phage titer (in plaque forming units (PFU) per $\mathrm{mL}$ ) on the test strain by the phage titer in PFU per $\mathrm{mL}$ on the S. pneumoniae R6 WT indicator strain. Adsorption of bacteriophages SCOP1 and Dp-1 was determining from independent triplicates as previously described [25].

\section{Isolation of S. pneumoniae R6 bacteriophage insensitive mutants}

S. pneumoniae $\mathrm{R} 6$ was grown in $\mathrm{BHI}+$ supplemented with $0.4 \%$ glycine to an $\mathrm{OD}_{600}$ of 0.4 under a $5 \% \mathrm{CO}_{2}$ atmosphere at $35{ }^{\circ} \mathrm{C}$. A $1 \mathrm{~mL}$ aliquot was mixed with $100 \mathrm{uL}$ of purified SOCP or Dp-1 $\left(10^{9}\right.$ PFU, multiplicity of infection of 10) and $50 \mu \mathrm{g} / \mathrm{mL}$ of catalase. After a 10 min incubation, the mixture was embedded in $10 \mathrm{~mL}$ of $0.7 \%$ low melting point agarose in $\mathrm{BHI}+$ supplemented 
with $0.4 \%$ glycine. This top agarose was poured onto a $1 \% \mathrm{BHI}+$ bottom agar supplemented with $0.4 \%$ glycine and incubated overnight at $35{ }^{\circ} \mathrm{C}$ under a $5 \% \mathrm{CO}_{2}$ atmosphere. Seven and six colonies resistant to Dp-1 and SOCP were obtained, respectively. Resistant colonies were picked out using a sterile toothpick, spread a few times on TSA blood agar and confirmed for phage resistance as described above. All clones had similar levels of resistance to the phage used for their selection and two resistant clones (one for Dp-1 and another for SOCP) were randomly chosen for whole-genome sequencing.

\section{Whole genome sequencing}

Genomic DNA was extracted from mutants S. pneumoniae $\mathrm{R} 6-\mathrm{SOCP}^{\mathrm{R}}$ and $\mathrm{R} 6-\mathrm{DP}^{\mathrm{R}}$ using the Wizard Genomic DNA Purification Kit (Promega) according to the manufacturer's instructions. Whole genome sequencing was performed using a 454 Life Sciences GS-FLX system (Roche). Genome sequencing, assemblies and comparative analyses were performed at the Institute for Integrative Systems Biology of Université Laval. Both assemblies covered $>99 \%$ of the S. pneumoniae R6 reference genome with a mean coverage depth of 53-fold and 47-fold for R6$\mathrm{DP}^{\mathrm{R}}$ and R6-SOCP ${ }^{\mathrm{R}}$, respectively. The detection of single nucleotide polymorphisms was performed using samtools (version 0.1.18), bcftools (distributed with samtools) and vcfutils.pl (distributed with samtools) [72]. All mutations deduced from massively parallel sequencing had at least 25 -fold coverage and were confirmed by PCR amplification and conventional DNA sequencing. The sequencing reads are available on the Sequence Read Archive database under the study number PRJEB9347 and sample accession ERS719580 and ERS7195801 for R6-DP1 ${ }^{\mathrm{R}}$ and R6-SOCP ${ }^{\mathrm{R}}$, respectively.

\section{RNA sequencing}

Total RNA was isolated from S. pneumoniae $\mathrm{R}^{\Delta \mathrm{spr} 0058}$ and R6 WT grown to mid-log phase in BHI using the Qiagen RNeasy Mini Kit (Qiagen) according to the manufacturer's instructions. RNAs were quantified using 2100 BioAnalyzer RNA6000 Nano chips (Agilent) and $1 \mu \mathrm{g}$ of total RNA was treated with Ribo-Zero ${ }^{\text {Tx }}$ rRNA Removal Kits (Epicentre). RNA-seq libraries were produced from $50 \mathrm{ng}$ of rRNA-depleted samples using the ScriptSeq ${ }^{\text {tix }}$ v2 RNA-Seq Library Preparation Kit (Epicentre). The libraries were analyzed using 2100 BioAnalyser High Sensitivity DNA chips and quantified by PicoGreen. The libraries were pooled, diluted to $8 \mathrm{pM}$ and sequenced on an Illumina MiSeq system using a 250 bp paired-ends reads protocol. Sequence reads from each strain were filtered based on quality score using Trimmomatic [73] and aligned to the genome of S. pneumoniae R6 using the software bwa with default parameters [74]. A total of 3,843,210 and 3,245,555 reads derived from S. pneumoniae R6 WT and $\mathrm{R}^{\Delta \mathrm{spr} 0058}$ mapped to the S. pneumoniae R6 reference genome, respectively. The maximum number of mismatches was 4 and the seed length was 32. Transcripts were assembled from the alignment files by using the Cufflinks pipeline [75]. Differential gene expression was computed with CuffDiff and genes with a false-discovery rate-adjusted $p$-value $\leq 0.05$ were considered as differentially expressed.

\section{DNA transformation and gene inactivation}

PCR fragments containing the mutations of interest were amplified using the Phusion High-Fidelity Polymerase (NEB) and primers listed in Additional file 5 at a final concentration of $0.5 \mu \mathrm{M}$. DNA fragments were amplified by 35 PCR cycles each made of $10 \mathrm{~s}$ denaturation, $20 \mathrm{~s}$ annealing and $30 \mathrm{~s}$ (for short 500bp PCR fragments) or $3 \mathrm{~min}$ (for long PCR fragments of $5 \mathrm{~kb}$ ) polymerisation (with an initial denaturation of $2 \mathrm{~min}$ and a final extension of $10 \mathrm{~min}$ ). PCR fragments were purified using the QIAquick PCR purification kit (QIAGEN). PCR fragments were co-transformed in S. pneumoniae competent cells along with 100ng of a short rpsL PCR fragment (500bp) amplified from S. pneumoniae CP1250 [40]. This co-transformed fragment is coding for a ribosomal protein S12 variant (Lys57Thr) conferring resistance to streptomycin that was used as a surrogate marker for the selection of transformants as previously described [35]. Competent cells were obtained by the dilution of an overnight $S$. pneumoniae culture 1:100 in $\mathrm{C}+\mathrm{Y}$ medium, $\mathrm{pH} 6.8$ (ref $47 \mathrm{FF}$ ). The diluted cultures were grown up to the onset of exponential phase before being concentrated ten times and frozen in $\mathrm{C}+\mathrm{Y}, \mathrm{pH}$ 6.8, $15 \%$ glycerol. For transformation, competent cells were thawed on ice, diluted ten times with $\mathrm{C}+\mathrm{Y}$ medium, $\mathrm{pH}$ 7.8, and complemented with $2 \mu \mathrm{g} / \mathrm{mL}$ of competence stimulating peptide 1 before being incubated for $15 \mathrm{~min}$ at $35{ }^{\circ} \mathrm{C}$ under a $5 \% \mathrm{CO}_{2}$ atmosphere. DNA was added to a final concentration of $2 \mu \mathrm{g} / \mathrm{mL}$ and the cultures were incubated for $1 \mathrm{~h}$ at $30^{\circ} \mathrm{C}$. Finally, the cultures were switched to $35{ }^{\circ} \mathrm{C}$ under a $5 \% \mathrm{CO}_{2}$ atmosphere for $1 \mathrm{~h}$ before being plated on CAT agar supplemented with $150 \mu \mathrm{g} / \mathrm{mL}$ streptomycin. The plates were incubated for $48 \mathrm{~h}$ at $35^{\circ} \mathrm{C}$ under a $5 \% \mathrm{CO}_{2}$ atmosphere and the resistant colonies were picked for further studies. Inactivation of spr0058 by insertional duplication mutagenesis in S. pneumoniae R6 was performed by cloning the middle section of spr0058 (using primers listed in Additional file 5) into the nonreplicative vector pFF6 as previously described [35]. The resulting plasmid was transformed into S. pneumoniae R6 as described above (without the need for rpsL cotransformation) and transformants were selected on CAT agar supplemented with $600 \mu \mathrm{g} / \mathrm{mL}$ kanamycin. 


\section{Replication of SOCP and Dp-1}

S. pneumoniae R6 was infected with SOCP or Dp-1 at a MOI of 0.1. Total DNA (i.e. S. pneumoniae genomic DNA together with phage DNA) was isolated at different time points after infection using the Wizard ${ }^{\bullet}$ Genomic DNA Purification kit (Promega) following manufacturer's instructions. Extracted DNA was digested with SspI, size-separated by electrophoresis, transferred to Nylon membrane and hybridized with $\left[\alpha-{ }^{32} \mathrm{P}\right] \mathrm{dCTP}$-labeled probes according to standard protocols [76]. Probes were obtained by PCR amplification of the holin gene from phage SOCP or Dp-1 and from the S. pneumoniae gene spr1443 using primers listed in Additional file 5.

\section{Electron microscopy}

Pneumococci were grown in BHI to an OD of 0.2. Cells were washed in $1 \times$ PBS, suspended in fixation buffer $(0.1$ M Cacodylate pH7.4, 2 \% glutaraldehyde) and incubated at $4{ }^{\circ} \mathrm{C}$ overnight. Specimen were prepared and analyzed using standard procedure by the Plate-forme d'Imagerie Moléculaire \& Microscopie of the Institute for Integrative Systems Biology of Université Laval using a Transmission Electron Microscope model JEOL 1010 at 100000× magnification. For each sample, cell wall thickness was measured from 30 bacteria ( 2 measures per bacteria) using ImageJ.

\section{Quellung reaction}

Quellung reaction was performed using pneumococcal type 2 antisera from the Statens Serum Institute as described in manufacturer's protocol. Samples were visualised under oil immersion using a Nikon Eclipse TE300 microscope and a $100 \times$ objective.

\section{Availability of supporting data}

Sequencing reads have been deposited at the EBI SRA database under the study accession number PRJEB9347.

\section{Additional files}

Additional file 1: Figure S1. Growth kinetics of S. pneumoniae R6 WT, R6-DP1 ${ }^{R}$ and R6-SOCPR. The growth of S. pneumoniae R6 WT (black dashed line), R6-DP1 ${ }^{R}$ (light grey line) and R6-SOCPR (dark grey line) in $\mathrm{BH}$ was monitored at one hour intervals for a period of $11 \mathrm{~h}$. Data are expressed as the mean of three independent experiments. (TIFF $122 \mathrm{~kb}$ )

Additional file 2: Figure S2. Cell wall thickness of S. pneumoniae R6 WT, R6-SOCPR and R6-DP1 ${ }^{R}$. Electron micrographs of S. pneumoniae R6 WT (A), R6-SOCP ${ }^{R}$ (B) and R6-DP1 ${ }^{R}$ (C) at 100000x magnification. (D) Mean cell wall thickness for S. pneumoniae R6 WT (black), R6-SOCPR (light grey) and $\mathrm{R} 6-\mathrm{DP} 1^{\mathrm{R}}$ (dark grey) measured from 30 bacteria with two measurements per bacteria. (TIFF $4146 \mathrm{~kb}$ )

Additional file 3: Figure $\mathbf{5 3}$. Gene expression profiling in S. pneumoniae $\mathrm{R}^{\Delta \mathrm{sp} p r 0058}$. Gene expression was compared between S. pneumoniae R6 WT and $R 6^{\Delta \text { spro058 }}$ by RNA-seq. The dots represent the 2043 genes from the $S$. pneumoniae R6 genome and their level of expression in R6 WT and $R 6^{\Delta s p r 0058}$ (represented in terms of fragments per kilobase of transcript per million fragments mapped) is indicated on the $x$-and $y$-axis, respectively. (TIFF $151 \mathrm{~kb}$ )
Additional file 4. Genes with an altered expression upon inactivation of spr0058 as determined by RNAseq. (PDF $128 \mathrm{~kb}$ )

Additional file 5. PCR primers used in this study. (PDF $23 \mathrm{~kb}$ )

\section{Abbreviations}

EOP: Efficiency Of Plaquing; MOI: Multiplicity Of Infection; PFU: Plaque Forming Unit; RNA-seq: RNA sequencing; rRNA: Ribosomal RNA; WT: Wildtype.

\section{Competing interests}

The authors declare that they have no competing interests.

\section{Authors' contributions}

PL, SM and MO designed the study. HG, PL and SO performed the experiments and analyzed the data. PL drafted the manuscript. SM and MO revised the manuscript and provided critical comments. PL, HG, SO, SM and MO approved the final version of the manuscript for publication.

\section{Acknowledgements}

We thank Mourad Sabri for useful discussion. This work was supported by an Emerging Team Grant from the Canadian Institutes of Health Research (CIHR) to SM and MO. SO is the recipient of a scholarship from the Programme Canadien de bourses de Francophonie (PCBF). SM holds a Tier 1 Canada Research Chair in Bacteriophages. MO holds a Tier 1 Canada Research Chair in Antimicrobial Resistance.

\section{Author details}

${ }^{1}$ Centre de recherche en Infectiologie du Centre de Recherche du CHU de Québec, Université Laval, 2705 Boul. Laurier, Québec, QC, Canada, G1V 4G2. ${ }^{2}$ Département de Microbiologie, Infectiologie et Immunologie, Faculté de Médecine, Université Laval, 1050, avenue de la Médecine, Québec, QC, Canada, GIV 0A6. ${ }^{3}$ Département de Biochimie, Microbiologie et Bio-informatique and PROTEO, Faculté des Sciences et Génie, Université Laval, Québec, QC, Canada. ${ }^{4}$ Félix d'Hérelle Reference Center for Bacterial Viruses and GREB, Faculté de Médecine Dentaire, Université Laval, Québec, QC, Canada.

Received: 25 June 2015 Accepted: 23 October 2015

Published online: 18 November 2015

\section{References}

1. Ardanuy C, de la Campa AG, Garcia E, Fenoll A, Calatayud L, Cercenado E, et al. Spread of Streptococcus pneumoniae serotype 8-ST63 multidrugresistant recombinant Clone, Spain. Emerg Infect Dis. 2014;20(11):1848-56.

2. Golden AR, Adam HJ, Gilmour MW, Baxter MR, Martin I, Nichol KA, et al. Assessment of multidrug resistance, clonality and virulence in non-PCV-13 Streptococcus pneumoniae serotypes in Canada, 2011-13. J Antimicrob Chemother. 2015;70(7):1960-4.

3. Jones RN, Sader HS, Mendes RE, Flamm RK. Update on antimicrobial susceptibility trends among Streptococcus pneumoniae in the United States: report of ceftaroline activity from the SENTRY Antimicrobial Surveillance Program (1998-2011). Diagn Microbiol Infect Dis. 2013;75(1):107-9.

4. McCarthy M. CDC calls for urgent action to combat rise of drug resistant pathogens. BMJ. 2013;347:f5649.

5. Laxminarayan R, Duse A, Wattal C, Zaidi AK, Wertheim HF, Sumpradit N, et al. Antibiotic resistance-the need for global solutions. Lancet Infect Dis. 2013;13(12):1057-98

6. McCullers JA, Karlstrom A, Iverson AR, Loeffler JM, Fischetti VA. Novel strategy to prevent otitis media caused by colonizing Streptococcus pneumoniae. PLoS Pathog. 2007;3(3):e28.

7. Loeffler JM, Djurkovic S, Fischetti VA. Phage lytic enzyme Cpl-1 as a novel antimicrobial for pneumococcal bacteremia. Infect Immun. 2003;71(11):6199-204.

8. Doehn JM, Fischer K, Reppe K, Gutbier B, Tschernig T, Hocke AC, et al. Delivery of the endolysin Cpl-1 by inhalation rescues mice with fatal pneumococcal pneumonia. J Antimicrob Chemother. 2013;68(9):2111-7.

9. Witzenrath M, Schmeck B, Doehn JM, Tschernig T, Zahlten J, Loeffler JM, et al. Systemic use of the endolysin Cpl-1 rescues mice with fatal pneumococcal pneumonia. Crit Care Med. 2009;37(2):642-9.

10. Diaz E, Lopez R, Garcia JL. EJ-1, a temperate bacteriophage of Streptococcus pneumoniae with a Myoviridae morphotype. J Bacteriol. 1992;174(17):5516-25. 
11. Gindreau E, Lopez R, Garcia P. MM1, a temperate bacteriophage of the type 23F Spanish/USA multiresistant epidemic clone of Streptococcus pneumoniae: structural analysis of the site-specific integration system. J Virol. 2000;74(17):7803-13.

12. McDonnell M, Lain R, Tomasz A. "Diplophage": a bacteriophage of Diplococcus pneumoniae. Virology. 1975;63(2):577-82.

13. Obregon V, Garcia P, Lopez R, Garcia JL. VO1, a temperate bacteriophage of the type 19A multiresistant epidemic 8249 strain of Streptococcus pneumoniae: analysis of variability of lytic and putative C 5 methyltransferase genes. Microb Drug Resist. 2003;9(1):7-15.

14. Romero A, Lopez R, Lurz R, Garcia P. Temperate bacteriophages of Streptococcus pneumoniae that contain protein covalently linked to the $5^{\prime}$ ends of their DNA. J Virol. 1990;64(10):5149-55.

15. Romero P, Croucher NJ, Hiller NL, Hu FZ, Ehrlich GD, Bentley SD, et al. Comparative genomic analysis of ten Streptococcus pneumoniae temperate bacteriophages. J Bacteriol. 2009;191(15):4854-62.

16. Ronda C, Lopez R, Garcia E. Isolation and characterization of a new bacteriophage, Cp-1, infecting Streptococcus pneumoniae. J Virol. 1981;40(2):551-9.

17. Ronda C, Lopez R, Tomasz A, Portoles A. Transfection of Streptococcus pneumoniae with bacteriophage DNA. J Virol. 1978;26(2):221-5.

18. Tiraby JG, Tiraby E, Fox MS. Pneumococcal bacteriophages. Virology. 1975;68(2):566-9.

19. Bernheimer HP. Lysogenic pneumococci and their bacteriophages. J Bacteriol. 1979;138(2):618-24.

20. Croucher NJ, Harris SR, Fraser C, Quail MA, Burton J, van der Linden M, et al. Rapid pneumococcal evolution in response to clinical interventions. Science. 2011;331(6016):430-4.

21. Ramirez $M$, Severina $E$, Tomasz $A$. A high incidence of prophage carriage among natural isolates of Streptococcus pneumoniae. J Bacteriol. 1999;181(12):3618-25.

22. Loeffler JM, Fischetti VA. Lysogeny of Streptococcus pneumoniae with MM1 phage: improved adherence and other phenotypic changes. Infect Immun. 2006;74(8):4486-95.

23. Sabri M, Hauser R, Ouellette M, Liu J, Dehbi M, Moeck G, et al. Genome annotation and intraviral interactome for the Streptococcus pneumoniae virulent phage Dp-1. J Bacteriol. 2011;193(2):551-62.

24. Martin AC, Lopez R, Garcia P. Analysis of the complete nucleotide sequence and functional organization of the genome of Streptococcus pneumoniae bacteriophage Cp-1. J Virol. 1996;70(6):3678-87.

25. Ouennane $S$, Leprohon P, Moineau S. Diverse virulent pneumophages infect Streptococcus mitis. PLoS One. 2015;10(2):e0118807.

26. Samson JE, Magadan AH, Sabri M, Moineau S. Revenge of the phages: defeating bacterial defences. Nat Rev Microbiol. 2013;11(10):675-87.

27. Bernheimer HP, Tiraby JG. Inhibition of phage infection by pneumococcus capsule. Virology. 1976;73(1):308-9.

28. Bender MH, Cartee RT, Yother J. Positive correlation between tyrosine phosphorylation of CpsD and capsular polysaccharide production in Streptococcus pneumoniae. J Bacteriol. 2003;185(20):6057-66.

29. Lopez R, Ronda C, Tomasz A, Portoles A. Properties of "diplophage": a lipid-containing bacteriophage. J Virol. 1977;24(1):201-10.

30. Bishop-Lilly KA, Plaut RD, Chen PE, Akmal A, Willner KM, Butani A, et al. Whole genome sequencing of phage resistant Bacillus anthracis mutants reveals an essential role for cell surface anchoring protein CsaB in phage AP50c adsorption. Virol J. 2012;9:246.

31. Castillo D, Christiansen RH, Dalsgaard I, Madsen L, Middelboe M. Bacteriophage resistance mechanisms in the fish pathogen Flavobacterium psychrophilum: linking genomic mutations to changes in bacterial virulence factors. Appl Environ Microbiol. 2015;81(3):1157-67.

32. Denes T, den Bakker HC, Tokman Jl, Guldimann C, Wiedmann M. Selection and Characterization of Phage-Resistant Mutant Strains of Listeria monocytogenes Reveal Host Genes Linked to Phage Adsorption. Appl Environ Microbiol. 2015;81(13):4295-305.

33. Billal DS, Feng J, Leprohon P, Legare D, Ouellette M. Whole genome analysis of linezolid resistance in Streptococcus pneumoniae reveals resistance and compensatory mutations. BMC Genomics. 2011;12:512.

34. Fani F, Brotherton MC, Leprohon P, Ouellette M. Genomic analysis and reconstruction of cefotaxime resistance in Streptococcus pneumoniae. J Antimicrob Chemother. 2013;68(8):1718-27.

35. Fani $F$, Leprohon $P$, Legare $D$, Ouellette $M$. Whole genome sequencing of penicillin-resistant Streptococcus pneumoniae reveals mutations in penicillin-binding proteins and in a putative iron permease. Genome Biol. 2011;12(11):R115

36. Fani F, Leprohon P, Zhanel GG, Bergeron MG, Ouellette M. Genomic analyses of DNA transformation and penicillin resistance in Streptococcus pneumoniae clinical isolates. Antimicrob Agents Chemother. 2014;58(3):1397-403.

37. Feng J, Lupien A, Gingras H, Wasserscheid J, Dewar K, Legare D, et al. Genome sequencing of linezolid-resistant Streptococcus pneumoniae mutants reveals novel mechanisms of resistance. Genome Res. 2009;19(7):1214-23.

38. Lupien A, Billal DS, Fani F, Soualhine $H$, Zhanel GG, Leprohon P, et al. Genomic characterization of ciprofloxacin resistance in a laboratory-derived mutant and a clinical isolate of Streptococcus pneumoniae. Antimicrob Agents Chemother. 2013;57(10):4911-9.

39. Lupien A, Gingras H, Bergeron MG, Leprohon P, Ouellette M. Multiple mutations and increased RNA expression in tetracycline-resistant Streptococcus pneumoniae as determined by genome-wide DNA and mRNA sequencing. J Antimicrob Chemother. 2015;70(7):1946-59.

40. Sung CK, Li H, Claverys JP, Morrison DA. An rpsL cassette, janus, for gene replacement through negative selection in Streptococcus pneumoniae. Appl Environ Microbiol. 2001;67(11):5190-6.

41. Hoskisson PA, Rigali S. Chapter 1: Variation in form and function the helix-turnhelix regulators of the GntR superfamily. Adv Appl Microbiol. 2009;69:1-22.

42. Labrie SJ, Samson JE, Moineau S. Bacteriophage resistance mechanisms. Nat Rev Microbiol. 2010;8(5):317-27.

43. Aravind L, Anantharaman V. HutC/FarR-like bacterial transcription factors of the GntR family contain a small molecule-binding domain of the chorismate lyase fold. FEMS Microbiol Lett. 2003;222(1):17-23.

44. Arai H, Akahira S, Ohishi T, Kudo T. Adaptation of Comamonas testosteroni TA441 to utilization of phenol by spontaneous mutation of the gene for a trans-acting factor. Mol Microbiol. 1999;33(6):1132-40.

45. Gorelik M, Lunin W, Skarina T, Savchenko A. Structural characterization of GntR/HutC family signaling domain. Protein Sci. 2006;15(6):1506-11.

46. Bidossi A, Mulas L, Decorosi F, Colomba L, Ricci S, Pozzi G, et al. A functional genomics approach to establish the complement of carbohydrate transporters in Streptococcus pneumoniae. PLoS One. 2012;7(3):e33320.

47. Jeong JK, Kwon O, Lee YM, Oh DB, Lee JM, Kim S, et al. Characterization of the Streptococcus pneumoniae BgaC protein as a novel surface beta-galactosidase with specific hydrolysis activity for the Galbeta1-3GlcNAc moiety of oligosaccharides. J Bacteriol. 2009;191(9):3011-23.

48. Terra VS, Homer KA, Rao SG, Andrew PW, Yesilkaya H. Characterization of novel beta-galactosidase activity that contributes to glycoprotein degradation and virulence in Streptococcus pneumoniae. Infect Immun. 2010;78(1):348-57.

49. Sijtsma L, Sterkenburg A, Wouters JT. Properties of the Cell Walls of Lactococcus lactis subsp. cremoris SK110 and SK112 and Their Relation to Bacteriophage Resistance. Appl Environ Microbiol. 1988;54(11):2808-11.

50. Ugalde RA, Coira JA, Brill WJ. Biosynthesis of a galactose-and galacturonic acidcontaining polysaccharide in Rhizobium meliloti. J Bacteriol. 1986;168(1):270-5.

51. Ugalde RA, Handelsman J, Brill WJ. Role of galactosyltransferase activity in phage sensitivity and nodulation competitiveness of Rhizobium meliloti. J Bacteriol. 1986;166(1):148-54.

52. Sijtsma L, Wouters JT, Hellingwerf KJ. Isolation and characterization of lipoteichoic acid, a cell envelope component involved in preventing phage adsorption, from Lactococcus lactis subsp. cremoris SK110. J Bacteriol. 1990;172(12):7126-30.

53. Lopez R, Garcia E, Garcia P, Ronda C, Tomasz A. Choline-containing bacteriophage receptors in Streptococcus pneumoniae. J Bacteriol. 1982;151(3):1581-90.

54. Larson TJ, Ehrmann M, Boos W. Periplasmic glycerophosphodiester phosphodiesterase of Escherichia coli, a new enzyme of the glp regulon. J Biol Chem. 1983;258(9):5428-32.

55. Fan X, Goldfine H, Lysenko E, Weiser JN. The transfer of choline from the host to the bacterial cell surface requires glpQ in Haemophilus influenzae. Mol Microbiol. 2001;41(5):1029-36.

56. Schmidl SR, Otto A, Lluch-Senar M, Pinol J, Busse J, Becher D, et al. A trigger enzyme in Mycoplasma pneumoniae: impact of the glycerophosphodiesterase GlpQ on virulence and gene expression. PLoS Pathog. 2011;7(9):e1002263.

57. Figueiredo TA, Sobral RG, Ludovice AM, Almeida JM, Bui NK, Vollmer W, et al. Identification of genetic determinants and enzymes involved with the amidation of glutamic acid residues in the peptidoglycan of Staphylococcus aureus. PLoS Pathog. 2012;8(1):e1002508. 
58. Munch D, Roemer T, Lee SH, Engeser M, Sahl HG, Schneider T. Identification and in vitro analysis of the GatD/MurT enzyme-complex catalyzing lipid II amidation in Staphylococcus aureus. PLoS Pathog. 2012;8(1):e1002509.

59. Zapun A, Philippe J, Abrahams KA, Signor L, Roper DI, Breukink E, et al. In vitro reconstitution of peptidoglycan assembly from the Gram-positive pathogen Streptococcus pneumoniae. ACS Chem Biol. 2013;8(12):2688-96.

60. Bui NK, Eberhardt A, Vollmer D, Kern T, Bougault C, Tomasz A, et al. Isolation and analysis of cell wall components from Streptococcus pneumoniae. Anal Biochem. 2012;421(2):657-66.

61. Sutherland E, Coe L, Raleigh EA. McrBC: a multisubunit GTP-dependent restriction endonuclease. J Mol Biol. 1992;225(2):327-48.

62. Pieper $U$, Pingoud A. A mutational analysis of the PD...D/EXK motif suggests that McrC harbors the catalytic center for DNA cleavage by the GTP-dependent restriction enzyme McrBC from Escherichia coli. Biochemistry. 2002:41(16):5236-44.

63. Kruger T, Wild C, Noyer-Weidner M. McrB: a prokaryotic protein specifically recognizing DNA containing modified cytosine residues. EMBO J. 1995;14(11):2661-9.

64. Pieper U, Brinkmann T, Kruger T, Noyer-Weidner M, Pingoud A. Characterization of the interaction between the restriction endonuclease McrBC from E. coli and its cofactor GTP. J Mol Biol. 1997;272(2):190-9.

65. Gast FU, Brinkmann T, Pieper U, Kruger T, Noyer-Weidner M, Pingoud A. The recognition of methylated DNA by the GTP-dependent restriction endonuclease $\mathrm{McrBC}$ resides in the N-terminal domain of McrB. Biol Chem. 1997;378(9):975-82.

66. Pieper U, Schweitzer T, Groll DH, Pingoud A. Defining the location and function of domains of McrB by deletion mutagenesis. Biol Chem. 1999:380(10):1225-30.

67. Pieper U, Schweitzer T, Groll DH, Gast FU, Pingoud A. The GTP-binding domain of McrB: more than just a variation on a common theme? J Mol Biol. 1999;292(3):547-56.

68. Valentino MD, McGuire AM, Rosch JW, Bispo PJ, Burnham C, Sanfilippo CM, et al. Unencapsulated Streptococcus pneumoniae from conjunctivitis encode variant traits and belong to a distinct phylogenetic cluster. Nat Commun. 2014:5:5411.

69. Donkor ES. Understanding the pneumococcus: transmission and evolution Front Cell Infect Microbiol. 2013:3:7.

70. Chewapreecha C, Harris SR, Croucher NJ, Turner C, Marttinen P, Cheng L, et al. Dense genomic sampling identifies highways of pneumococcal recombination. Nat Genet. 2014;46(3):305-9.

71. Chewapreecha C, Marttinen P, Croucher NJ, Salter SJ, Harris SR, Mather AE, et al. Comprehensive identification of single nucleotide polymorphisms associated with beta-lactam resistance within pneumococcal mosaic genes. PLoS Genet. 2014:10(8):e1004547.

72. Li H, Handsaker B, Wysoker A, Fennell T, Ruan J, Homer N, et al. The Sequence Alignment/Map format and SAMtools. Bioinformatics. 2009;25(16):2078-9.

73. Bolger AM, Lohse M, Usadel B. Trimmomatic: a flexible trimmer for Illumina sequence data. Bioinformatics. 2014;30(15):2114-20.

74. Li H, Durbin R. Fast and accurate short read alignment with BurrowsWheeler transform. Bioinformatics. 2009;25(14):1754-60.

75. Trapnell C, Williams BA, Pertea G, Mortazavi A, Kwan G, van Baren MJ, et al. Transcript assembly and quantification by RNA-Seq reveals unannotated transcripts and isoform switching during cell differentiation. Nat Biotechnol. 2010;28(5):511-5.

76. Sambrook J, Fritsch EF, Maniatis T. Molecular cloning. New York: Cold Spring Harbour laboratory; 1989

77. Hoskins J, Alborn Jr WE, Arnold J, Blaszczak LC, Burgett S, DeHoff BS, et al. Genome of the bacterium Streptococcus pneumoniae strain R6. J Bacteriol. 2001;183(19):5709-17.

78. Lanie JA, Ng WL, Kazmierczak KM, Andrzejewski TM, Davidsen TM, Wayne $\mathrm{KJ}$, et al. Genome sequence of Avery's virulent serotype 2 strain D39 of Streptococcus pneumoniae and comparison with that of unencapsulated laboratory strain R6. J Bacteriol. 2007;189(1):38-51.

\section{Submit your next manuscript to BioMed Central and take full advantage of:}

- Convenient online submission

- Thorough peer review

- No space constraints or color figure charges

- Immediate publication on acceptance

- Inclusion in PubMed, CAS, Scopus and Google Scholar

- Research which is freely available for redistribution

Submit your manuscript at www.biomedcentral.com/submit 